Research Article

\title{
Cost Control and Project Cost Analysis of Intelligent Building under Internet of Things
}

\author{
Shengran Xi, ${ }^{1}$ Chunxia Zhang ${ }^{10},{ }^{1}$ Zixi Cai, ${ }^{2}$ and Yikang Xu ${ }^{1}$ \\ ${ }^{1}$ School of Civil Engineering, Shanghai Normal University, Shanghai 200234, China \\ ${ }^{2}$ School of Finance and Business, Shanghai Normal University, Shanghai 200234, China \\ Correspondence should be addressed to Chunxia Zhang; 1000464637@smail.shnu.edu.cn
}

Received 6 August 2021; Accepted 27 August 2021; Published 16 September 2021

Academic Editor: Fazlullah Khan

Copyright ( $\odot 2021$ Shengran Xi et al. This is an open access article distributed under the Creative Commons Attribution License, which permits unrestricted use, distribution, and reproduction in any medium, provided the original work is properly cited.

The conventional urban system has a very disorganized and unmanageable mode of operation, and the information between the systems has not been efficiently shared and interconnected. Smart cities and intelligent building will be the future trend of urban development. With the advent of new concepts and techniques brought by the Internet of Things (IoT) across the world, all fields of life are progressively shifting towards smart societies. Based on the prediction algorithm of the IoT, this paper constructs the cost control and cost prediction model of intelligent building. Combined with the characteristics of the current smart city construction, three engineering cost schemes (S0, S1, and S2) are constructed, and the cost simulation of these three examples is carried out to verify the cost control and cost prediction model of the intelligent building. Experimental results show that the total cost of each cost level of the three schemes is lower than the conventional total cost, and the total cost change rate ranges are $-121.6 \% \sim-27.6 \%,-210.3 \% \sim-47.2 \%$, and $-150.3 \% \sim-22.3 \%$, respectively. The proposed smart city cost prediction model can reduce project cost, which has great economic significance for the construction of smart cities.

\section{Introduction}

The development of cities is a symbol of the high-level form of human society entering the civilized era and human social life. The urbanization process has been increasing, the cities have expanded, and the status of cities as economic hubs has increased [1]. The growth in human productivity has also added to the development of urban functions. The rapid development of cities is also creating social problems such as inefficient management, traffic congestion, environmental pollution, and inefficient emergency response systems. After 70 years of development, China's urbanization process has been increasing. In this urbanization process, people's standards of life have been continuously improved. The idea of smart city development based on next-generation technologies such as the IoT has become an innovative model for future urban expansion. Smart cities are the inevitable output of the growth of urban models. The smart building of smart cities can considerably solve the problems associated with urban development, improve information management, and encourage the progress of high-level industries and businesses nationwide [2].

The smart city is a new concept based on IoT and related data technologies, big data mining, and analysis technology as the core [3]. In recent years, the construction industry combines smart building with IoT techniques, and many scholars try to combine various emerging technologies with smart city development to reduce construction costs. Vihola and Kurvinen [4] reduced construction time and reduced the cost in the construction process by installing radio frequency identification (RFID) on prefabricated building components combined with a computer-aided design (CAD) model. Tuulia et al. [5] used the $4^{\text {th }}$ level of building information (BIM4) and engineer to order (ETO) prefabricated building systems to plan and control on-site assembly transportation and reduce transportation costs. Ruonavaara [6] pointed out that the main obstacle to the use of prefabrication is the change of design in the later stage. In prefabrication, different components of a structure are assembled in a factory or another manufacturing 
site and transported to the construction site where the building is to be placed. The author also indicated that the implementation of legislation and the adoption of design, construction, and procurement methods can promote the use of prefabricated components. Martti [7] studied the evolution of prefabrication technology in the development of high-rise residential buildings in Hong Kong. Puustinent and Viitanen [8] used the decision, test, and evaluation laboratory (DETL) model and analytical network process (ANP) method to quantify the causality of China's construction industry and prioritize the key delay factors according to their importance to reduce the construction cost of building in a smart city.

From the perspective of building performance and characteristics, researchers have studied the performance and characteristics of buildings. For example, Akbar [9] employed silica fume and fly ash mixture according to standards of American Society for Testing and Materials (ASTM) and British Standards (BS) and used treated domestic wastewater to produce self-compacting concrete (SCC). Newman and Kenworthy [10] analyzed the green development opportunities of prefabricated buildings for smart city development from the perspective of the supply chain and expounded the strategy of obtaining green benefits. In another study, Puustinen et al. [11] analyzed the household electricity expenditure of Germany in 2017 and found that the income obtained by users with the IoT system through fit policy can not only compensate for the increasing smart building surcharge year by year but also obtain certain net income. Stephen and Peter [12] evaluated the impact of different fit schemes on the investment tendency of intelligent buildings by quantifying the relationship between fit grades. To solve this problem, Hauge et al. [13] introduced the intelligent cost of the IoT into the total cost of the building. After adding the intelligent cost of the IoT, the final total cost of the building that had the intelligent building system installed and achieved the project cost target was only $1 / 3$ of that without the intelligent building system. Jin et al. [14] developed the Joint Smart City Platform (SCP) and applied it to the European urban smart waste management systems. The platform integrated the IoT and metro access networks to provide intelligent facilities to citizens and enable smart city function.

Although the above-mentioned methods have solved the cost problem of IoT equipment to a certain extent, in the face of a large number of new equipment investments, these algorithms cannot effectively predict the cost, so there is a need to adjust the prediction function combined with the development speed of the smart city, to achieve the purpose of cost control.

In this paper, an intelligent cost control method for the construction of a smart city is proposed. The Monte Carlo method is used to verify the effectiveness of the cost prediction function in the total cost adjustment under different construction costs. Taking a residential building in Nanchang city of China as an example, three different cost prediction functions (S0, S1, S2) are designed. Experimental results show that the total cost of each cost level of the three schemes is lower than the conventional total cost.
The remaining sections of the paper are structured as follows: Section 2 provides an overview of the current building construction methods. In Section 3 the proposed construction cost prediction model is discussed. Sections 4 and 5 are about results and discussion, respectively, and Section 6 concludes the proposed work.

\section{IoT Intelligent Building and Cost Budget Model}

2.1. Development Demand of Intelligent Building. In China, housing construction has shifted from increasing housing supply to meeting rigid demands, demolishing old buildings, and building new ones to improve the quality and functions of buildings. Large-scale demolition and construction have become the key mode of the intelligent building industry [14]. The objective of large-scale demolition and new construction is to improve building performance and optimize land use. The main driving force behind it is the high land prices in China [14]. However, if such large-scale demolition and construction continue, the construction of houses will become a continuous industry [15]. Therefore, the resulting demand for steel and building materials will continue, the production of steel and building materials will continue to flourish, and the construction cost will be increased. Changing the upgradation mode of existing buildings from large-scale demolition and construction to maintenance and transformation can greatly reduce the consumption of building materials, thus reducing the construction cost in the production process of building materials. The construction industry should be transformed from building new houses to repairing old ones. Since the cement production process emits a lot of carbon dioxide, to solve this problem, we need to change the current housing construction methods and building materials. Before the industrial revolution, there was no cement in the history of housing construction in China. The great wall and huge palaces were built by using traditional techniques. Cement is only a building material developed in the past 200 years and has formed a construction method based on it [16]. Low-carbon development is likely to require a revolution in the construction industry, and its fundamental starting point is to replace high construction cost cement with new low-carbon and zero-carbon building materials and develop new building structures and housing construction methods based on the characteristics of new building materials. It is difficult for the future energy system to completely avoid carbon dioxide using fossil energy. However, where to store the solidified or liquefied carbon dioxide is the most difficult problem to solve in the cost control path of intelligent building interconnection [17]. If carbon dioxide is synthesized into new building materials in a certain way to make the building structure a carbon storage space, it can not only solve the construction cost of the building materials production process but also make the building become the carrier of carbon fixation, which will make a significant contribution to the realization of the cost control goal of intelligent building network in the future. 
2.2. IoT Construction Cost Budget Model. We used theoretical derivation to calculate the cost budget of residential families. From the perspective of residential families, the life cycle cost of residential buildings includes three parts: initial acquisition cost $C_{0}$, disaster loss (DL), and maintenance cost (MC) [18].

Assuming that the residents already have residential buildings that meet their requirements but have not yet reached the seismic toughness level (hereinafter referred to as buildings with zero-star toughness level), the residential buildings will be upgraded to the seismic toughness level "s," and the initial acquisition $\operatorname{cost} C_{0}$ and $s$ at which families are willing to build are their decision variables [19]. Under the given probability of earthquake occurrence, $\mathrm{E}(\mathrm{DL}, s)$ is the expected value of the total loss caused by the earthquake disaster under the seismic toughness level " $s$."

$$
\begin{aligned}
E(\mathrm{DL}, s) j & =\frac{1 / 2 u_{j} \sum_{i=1}^{n_{j}} \sum_{r=1}^{n_{j}}\left|y_{j i}-y_{j r}\right|}{n_{j}^{2}}, \\
G_{E(\mathrm{DL}, s)} & =\sum_{j=1}^{k} G_{j j} p_{j} s_{j} .
\end{aligned}
$$

It is assumed that the MC in the whole life cycle of the building has nothing to do with the seismic grade and is still recorded as a constant MC. The expected cost of the whole life cycle of the S-class building with seismic toughness is calculated as

$$
\ln \frac{\left(\mathrm{MC}_{\mathrm{it}} / \mathrm{MC}_{\mathrm{it}}-1\right)}{s}=\alpha+\beta \ln \mathrm{MC}_{\mathrm{it}}-1+\phi X_{\mathrm{it}}-1+v_{i}+\tau_{t} \text {. }
$$

Assuming that there is no difference in the utility of residential buildings with different seismic toughness levels except for the difference in seismic performance (which has been reflected as disaster loss (DL)), the goal of maximizing utility in the whole life cycle of building faced by the households as decision-makers is equivalent to the goal of minimizing cost in the whole life cycle $[20,21]$. Therefore, if and only if the life cycle cost does not increase, the DL is calculated as

$$
\mathrm{DL}_{t 1}[\mathrm{MC}]=\sum_{j} \frac{\cos (w 1 / i, w 2 / j)}{s} .
$$

If the residents and families are willing to improve the seismic toughness level of buildings, therefore, when the residential building is upgraded to grade $s$, the maximum initial acquisition cost at which the family is willing to build is computed as

$$
\begin{aligned}
\mathrm{WTP}_{t} & =\sum_{j=2}^{k} \sum_{h=1}^{j-1} G_{j h}\left(p_{j} s_{h}+p_{h} s_{j}\right) D_{j h}\left(1-P 1_{j h}\right), \\
P 1_{j h} & =\frac{d_{j h}-P_{j h}}{d_{j h}+P_{j h}},
\end{aligned}
$$

where PJ is the annual occurrence probability of class $J$. The earthquakes that affect buildings are divided into rare earthquakes and fortification earthquakes. Correspondingly,
$P 1$ is the probability of rare earthquakes, $P 2$ is the probability of fortification earthquakes, and $P 3$ is the probability of no earthquakes that affect buildings. DJ is the total loss of the building with toughness grade $s$ under the condition of class $J$ and is equivalent to

$$
D_{j h}=\frac{\int_{0}^{\infty} \mathrm{d} F_{j}(y) \int_{0}^{y}(y-x) \mathrm{d} F_{h}(x)}{K},
$$

where $K$ is the discount factor and $n$ is the design service life of the building. Equation (5) shows that the cost budget of the family is equal to the present value of the expected earthquake loss reduced by the improvement of the building's seismic toughness in the whole life cycle. Although (5) provides a basic idea for the quantitative evaluation of the cost budget for the improvement of seismic toughness level of residential buildings, it is still insufficient to apply it directly to practical calculation. Existing studies show that the risk aversion coefficient of ordinary people is usually between 0.5 and 10 , which is calculated as

$$
\theta=-\frac{1}{T} \ln (1+\beta)
$$

Equation (6) reflects the life cycle cost of buildings calculated based on the objective expected value of earthquake loss. However, when families make decisions, they rely on their subjective judgment of their utility value, that is, their subjective utility. Therefore, they may also be affected by their subjective risk attitude and even irrational value perception factors $[22,23]$. That is to say, when the cost is 0 , the efficiency value reaches the maximum value of 1 , and the maximum efficiency value reaches the minimum value of 0 . Under the assumption of expected utility theory, the decision-making goal of household is to maximize the subjective utility of the whole life cycle. Therefore, if and only if the whole life cycle utility does not decrease, residents and families are willing to improve the seismic toughness level of buildings, that is,

$$
\begin{aligned}
& G=\frac{\sum_{j=1}^{k} \sum_{h=1}^{k} \sum_{t=1}^{n_{j}} \sum_{r=1}^{n_{h}}\left|y_{i j}-y_{h r}\right|}{2 n^{2} u}, \\
& u_{h} \leq u_{j} \leq \ldots \leq u_{k} .
\end{aligned}
$$

Since families are faced with existing buildings whose seismic toughness level has been determined to be zero, and the corresponding initial cost is 0 , when the seismic toughness level of sporadic buildings is increased to $s$, the cost budget WTPS of residents' families can be expressed as

$$
\mathrm{WTP}_{t}=\tanh \left(w_{c} x_{t}+u_{c}\left(r_{t} \Theta h_{t-1}\right)+b_{c}\right) .
$$

This shows that the utility loss caused by the construction premium is equal to the utility loss reduced by the upgrading of building resilience [24]. Equation (8) substitutes the objective expectation value with the subjective utility function of cost, which can reflect the influence of residents' family's subjective risk attitude: 


$$
\begin{aligned}
\sigma t & =\frac{\sqrt{1 / n \sum_{i=1}^{n}\left(\mathrm{WTP}_{\mathrm{it}}-\mathrm{WTP} s_{\mathrm{it}}\right)^{2}}}{\mathrm{WTP}_{\mathrm{it}}}, \\
u_{(j / t)} & =w_{i j} A_{i} .
\end{aligned}
$$

Based on the premise of complete rationality of the decision-maker, it is assumed that the decision-maker makes the optimal decision based on the objective probability, and the degree of reaction to the loss and profit is the same. However, in real life, the decision-making of resident families is usually not completely rational. Prospect theory relaxes the hypothesis of the rational person and introduces the influence of irrational value perception factors of decision-makers [25]. Prospect theory has proved to be more consistent with the individual decision-making model observed in social experiments, so it has become a widely used risk decision-making theory. Prospect theory considers the influence of irrational value perception factors from two aspects [26]. First of all, it is assumed that decision-makers have a risk-chasing attitude to loss and a risk aversion attitude to profit. Accordingly, the value function $v(x)$ of the decision-maker is a piecewise function with 0 as the cut-off point:

$$
v(x)_{j}=\sum_{i} c_{i j} u_{(j / t)}, \frac{\lambda}{c_{i j}} * \frac{\alpha+\beta \ln \mathrm{FI}_{\mathrm{it}}}{X}=\frac{e^{b_{i j}}}{\sum_{k} e^{b_{i k}}}
$$

In this paper, 0 is taken as the reference point, and the value function $v(x)$ reflects the subjective value perceived by the decision-maker based on the change of $X$ :

$$
\ln \left(\frac{X_{\mathrm{it}}}{X_{\mathrm{it}}-1}\right)=\frac{\alpha+\beta \ln \mathrm{FI}_{\mathrm{it}}}{X},
$$

where the values of $\alpha$ and $\beta$ are generally between 0.3 and 1.0 and the value of $\lambda$ is generally between 0.3 and 2.5. Another core assumption of prospect theory is that decision-makers make risk decisions through subjective probability rather than objective probability. Meanwhile, there are differences between loss probability and profit probability. Therefore, the decision weight function $(P)$ corresponding to the objective probability $p$ is introduced in prospect theory:

$$
\amalg(p)_{t}=z_{t} \Theta h_{t-1}+\left(1-z_{t}\right) \Theta h_{t} * W,
$$

where $\mathrm{p}$ represents the objective probability, $\Pi+$ and $W+$ are the decision-making weight functions in the case of profit, and $\Pi$ and $W$ are the decision-making weight functions in the case of loss. Existing studies show that the values of $\gamma$ and $\delta$ are between 0.5 and 1.0. The decision weight function drawn in this interval is higher than the $45^{\circ}$ line when $p$ is small, but lower than the $45^{\circ}$ line when $p$ is large. Under prospect theory, the goal of decision-makers is to minimize the loss of the expected prospect value in the whole life cycle of the building [27]. Because of the strict distinction between loss and profit in prospect theory, all cost variables in the value function are preceded by a negative sign which indicates a loss. In summary, if and only if the loss of the whole life cycle prospect value does not increase, then

$$
f(x)=\frac{1}{\mathrm{Nh}} \sum_{i=1}^{N} k\left(\frac{X_{i}-x}{h}\right)=P,
$$

If the residents and families are willing to improve the seismic toughness level of buildings, then when the seismic toughness level of the building is upgraded from zero stars to $s$ level, the cost budget WTPS of the residential family can be calculated using

$$
k(x)=\frac{1}{\sqrt{2 \pi}} \exp \left(-\frac{x^{2}}{2}\right) .
$$

Equation (14) shows that under the prospect theory, the loss of expected prospect value caused by the construction premium of households is equal to the loss of expected prospect value caused by the earthquake in the whole life cycle reduced after the building toughness level is improved. Compared with (13), (14) considers not only the decisionmakers' risk attitude but also their subjective cognition of risk probability and the tendency of "risk pursuit" of loss, which may be more accurate and close to the choice behavior of households in reality.

\section{Cost Control and Engineering Cost of Intelligent Building}

3.1. Contents. Based on the prediction algorithm of the IoT, we constructed the cost control and cost prediction model of intelligent buildings, in which the cost prediction mainly uses the prediction function to predict the cost of intelligent buildings in a smart city. We established three cost prediction functions and examined the influence of each function on the total construction cost under different engineering and construction cost levels. To verify the effectiveness of cost prediction functions in different types of buildings, nine construction cost grades were selected. Under each construction cost grade, the Monte Carlo method was employed to simulate the construction cost 200 times, and the average value was taken as a construction cost sample. Combined with the characteristics of the current smart city construction, three engineering cost cases were constructed, and the cost simulation of these three cases was carried out to verify the proposed cost control and cost prediction model of the intelligent building as well as the accuracy and effective range of the prediction function. Taking the standard building as an example, when the project cost level is Preengineering level 0 (0PEB), 0.2PEB, 0.4PEB, 0.6PEB, 0.8PEB, 1.0PEB, and 1.2PEB, the required installation area of IoT board was $0,8,14,23,27,35$, and 42 (M2), respectively.

\subsection{Cost Control and Cost Prediction Model of Intelligent Building}

3.2.1. The Intelligent Feature of Engineering Cost Calculation. Recently, some industries and enterprises are increasingly developing their own cost information databases, establishing intelligent computation models and methods that 
provide data and information guidance, and can more intelligently calculate the bill of quantities, bid quotations, design changes, on-site visas, and project settlements. With the integration of big data in the IoT, the influence of various factors in the building project implementation process can be judged more quickly and accurately. Moreover, the redundant links in the construction process can be reduced, thereby reducing costs and reducing engineering costs caused by human factors. In addition, this will improve the operating and implementation accuracy of project cost and improve the level of project cost informatization. As the supporting technology of cost calculation, the IoT technology development in big data analysis, image recognition, and deep learning will break through the bottleneck of largescale data modeling in the information integration of engineering cost environment systems and improve the level of informatization and intelligence. The cost control architecture is shown in Figure 1.

3.2.2. IoT-Based Construction Cost Prediction and Information Management Model. With the gradual development of cloud technology, big data, and IoT, the management of project cost information is further improved [28]. The development of the project cost information management model of IoT has both objective needs and a technical basis. The project cost information management model using IoT is based on the project cost information database and building information modeling (BIM). With the integration of big data and IoT computing technology, the basic modules and main systems of project cost information management cost prediction model are constructed to fully realize the functions of information collection, intelligent decisionmaking, and supervision and serve the construction and development of intelligent project cost [29]. The intelligent project cost information management model integrates various elements to realize intelligent data collection, intelligent listing, intelligent decision-making, and supervision.

\section{Results}

4.1. Construction Cost. There are two ways to obtain the standard construction cost: the first is to obtain the construction cost data from the construction cost database; the second is to take the simulated construction cost as the standard construction cost based on the local typical meteorological parameters and related building parameters and then determine the unknown parameters in the cost prediction function.

As shown in Figure 2, firstly, according to the relationship between the construction cost and the transaction volume of the IoT, the construction cost level was divided, and the corresponding required number of IoT boards was calculated. Secondly, according to the current market price of IoT board and electricity, the average annual initial investment of IoT system and the operation cost of the standard building are determined, and the sum of the two is the total conventional cost of the building. Moreover, the installation area, the investment at the beginning of the year, and the building operation cost of the IoT board were also calculated, and the intelligent cost of the IoT was calculated by using the cost prediction function, to obtain the total cost of the building.

4.2. Connection Cost. Figure 3 shows the cost of connecting different components in a smart building. Each component is represented by one application module. It is clear that the cost of intelligent building networking components is getting lower and lower, and the transaction cost of IoT is lower than that of coal power. The main difficulty of the development of IoT techniques is access and consumption. When light storage, direct, and flexible transformation is not realized in the buildings, large-scale building interconnection may bring some impact on the power grid when the access conditions are limited. Therefore, IoT based power consumption systems will provide proper management of power consumption in a smart building.

4.3. Cost Control Effect. To obtain the cost control effect of the proposed intelligent building more accurately, we employed a genetic algorithm and artificial neural network to visualize the cost control effect. As shown in Figure 4, the overall error of the test sample is the smallest, the test result is close to the real value, and the error value is far less than the relative error value of the artificial neural network method, which indicates that the optimized result of genetic algorithm is more consistent with the real value and the calculation result is more accurate.

4.4. Project Cost. The total construction cost is closely related to the project cost level. The relationship between the total standard construction cost and the project cost level is shown in Figure 5. Without the intelligent mechanism of the IoT, the total conventional construction cost increases with the increase of the project cost level. When the intelligent mechanism of the Internet of Things is introduced, the total cost curves of the three schemes are concave curves, and the lowest total cost is 512.5 Yuan, 0 Yuan, and 476.8 Yuan at 1.0PEB, 1.0PEB, and 0.8PEB, respectively.

The influence of project cost level and construction cost level on the total construction cost is shown in Figure 6. In scheme S0, when the intelligent mechanism of IoT is applied, the minimum total construction cost is expected to occur at 1.0PEB, and the minimum total construction cost of 0.4BEC 0.6BEC, $0.8 \mathrm{BEC} \sim 1.6 \mathrm{BEC}$, and 1.8 BEC 2.0 BEC will occur at $1.2 \mathrm{PEB}, 1.0 \mathrm{PEB}$, and $0.8 \mathrm{PEB}$, respectively, except that the cost level is $0.4 \mathrm{BEC}(\delta)=51 \%)$ and $0.6 \mathrm{BEC}$ $(\delta=-11.42 \%)$, but the construction cost error of other cost levels was kept around $4 \%$. At the same time, considering the two factors of engineering cost level and construction cost level, this paper studied the influence of IoT intelligent mechanism on the total construction cost under the three schemes when the two factors change.

Table 1 shows that the total cost will increase with the increase of project cost level after reaching the lowest point. 


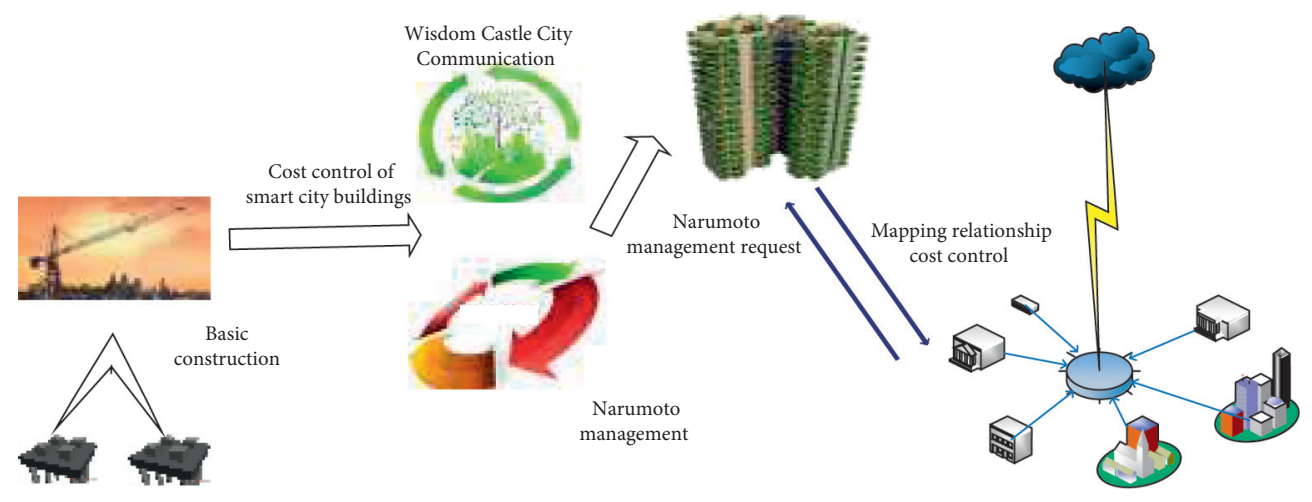

FIGURE 1: Cost control structure.

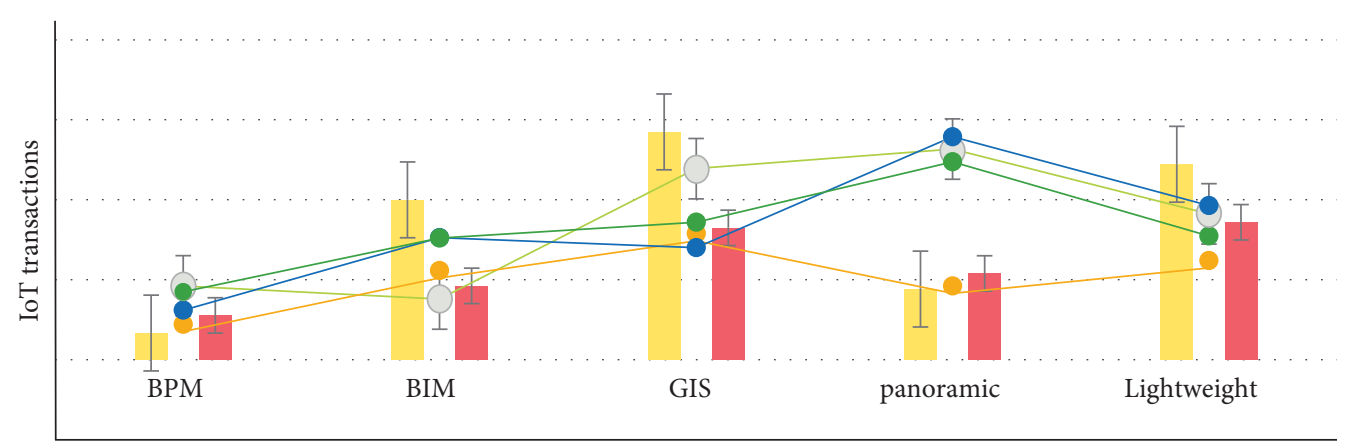

Construction cost

BIM

$\mathrm{OA}$

GIS

FIgUre 2: Building cost and IoT transaction volume.

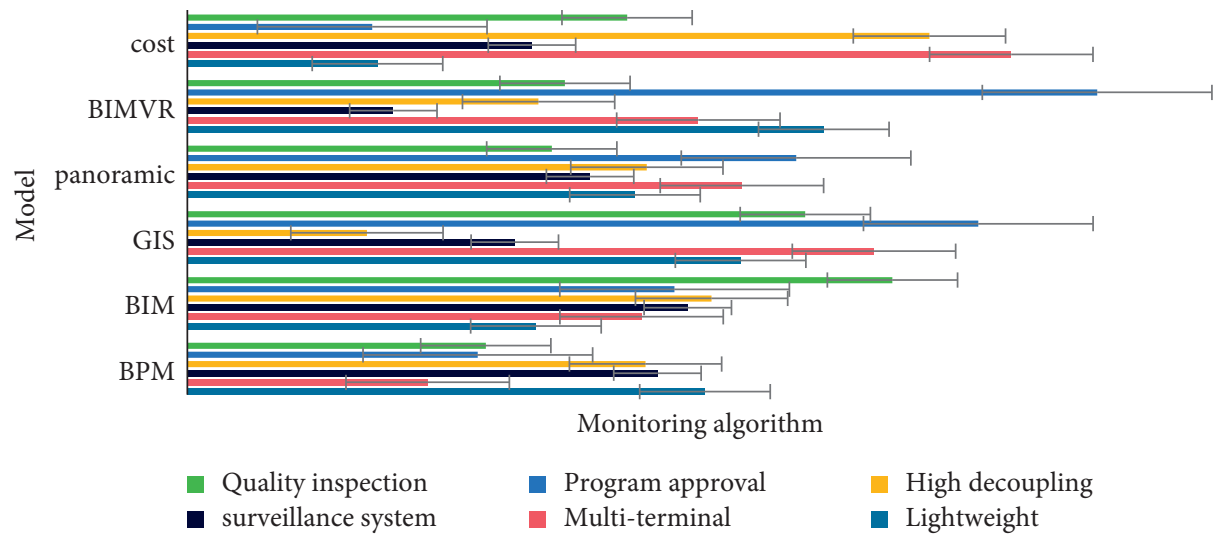

FIgURE 3: The cost of connected components for smart buildings.

In addition, compared with the conventional total cost, the total cost change rate is different under different project cost levels. The cost change rate $\sigma$ ranges of S0, S1, and S2 are $-50.9 \% \sim 100 \%$, $-97.5 \% \sim 100 \%$, and $-50.0 \% \sim 50.0 \%$, respectively. Similarly, schemes S0, S1, and S2 can get a bonus in the design of $0.6 \mathrm{PEB}, 0.2 \mathrm{PEB}$, and $0.4 \mathrm{PEB}$, respectively, and the higher the engineering cost level of the building, the higher the economic benefit of the building obtained by users.
4.5. Changing Trend of Different Construction Cost Levels. Table 2 shows that under the intelligent mechanism of the IoT of the three schemes, the changing trend of the total construction cost under different construction cost levels is similar. The total construction cost first decreases with the increase of the construction cost level and then increases with the increase of the construction cost level after reaching a certain value. Under the same construction cost level, there are differences in the total 


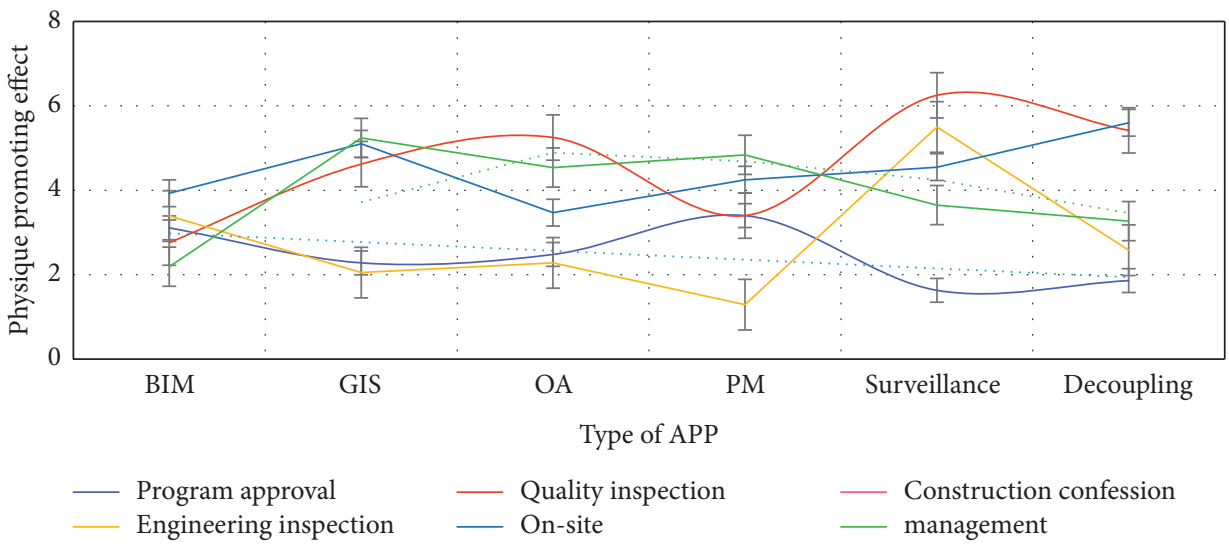

Figure 4: The effect of building visual processing based on deep learning genetic algorithm.
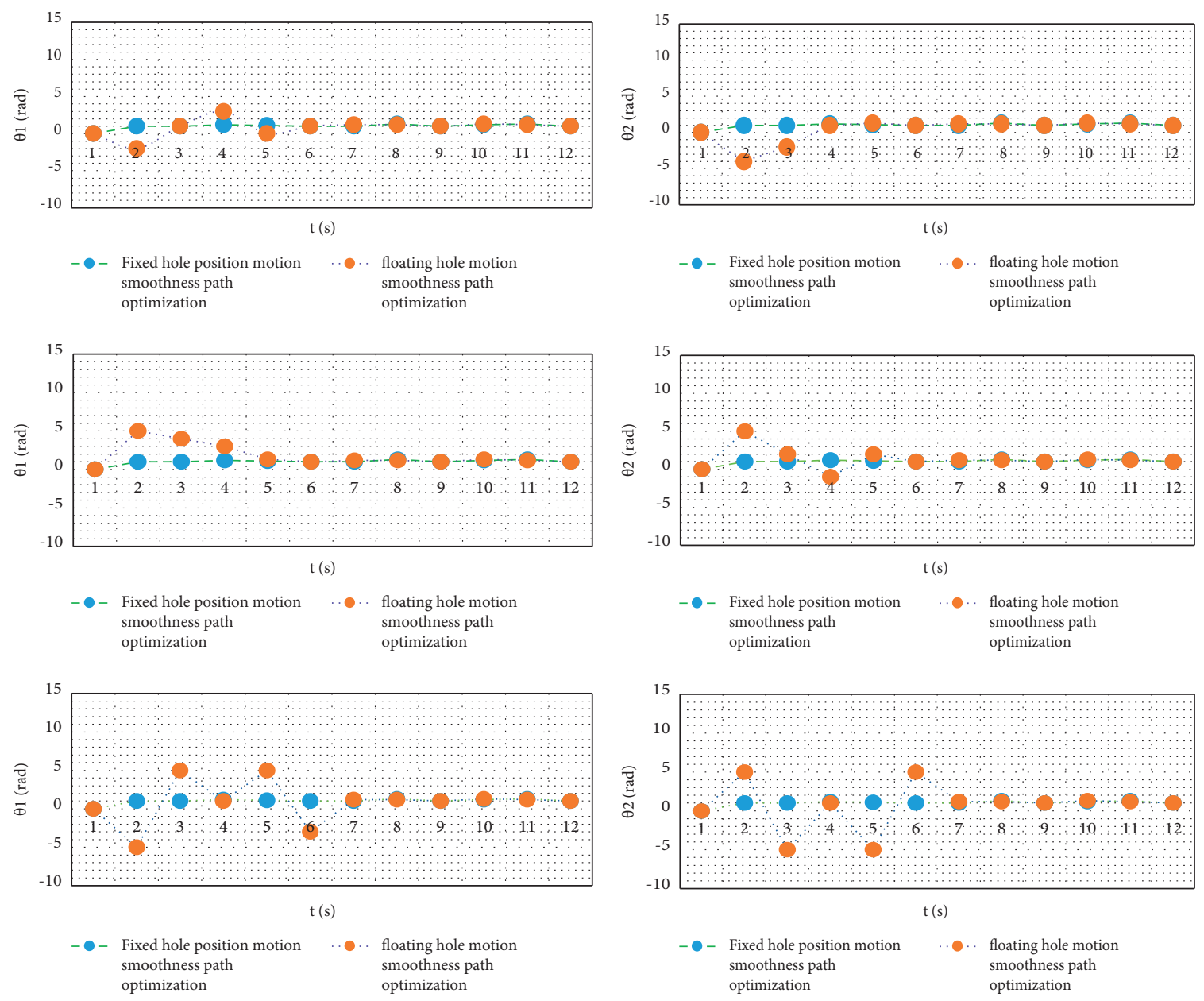

FIGURE 5: Total cost of standard construction and project cost grade.

construction cost of different construction cost levels, which is caused by different initial investment and operation costs. Ideally, for buildings with different cost levels in scheme $\mathrm{S} 0$, the lowest total cost corresponding to the project cost level should be 1.0PEB. It was found that when the building cost level was $0.4 \mathrm{BEC} \sim 0.6 \mathrm{BEC}$ and $0.8 \mathrm{BEC} \sim 92 \mathrm{HVAC}$, the lowest points of the total building cost curve were, respectively, at 1.2PEB, 1.0PEB, and
$0.8 \mathrm{PEB}$, which are all near $1.0 \mathrm{PEB}$. Therefore, it can be considered that the cost prediction function is suitable for buildings with a cost level of 0.4BEC 2.0BEC.

4.6. Virtual Reality Simulation. As shown in Figure 7, virtual reality can be visually stimulated in BIMCC management to realize the simulation of the IoT terminal. The DC charging 


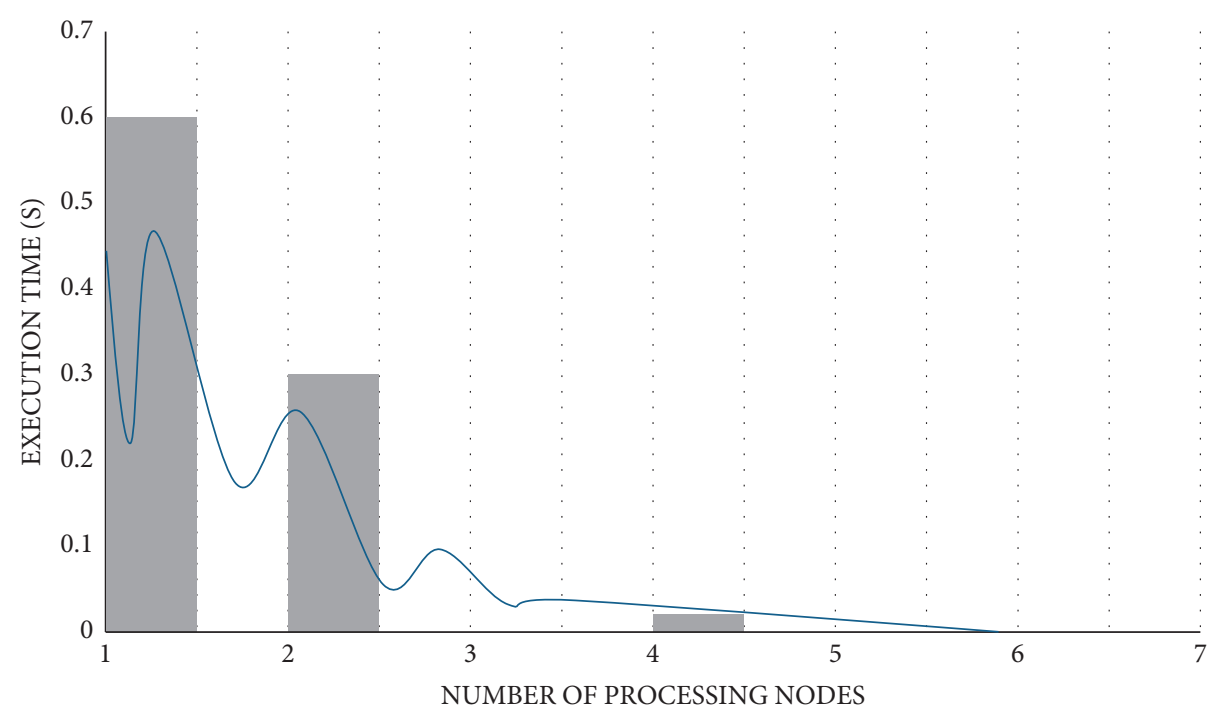

Figure 6: Project cost grade, construction cost grade, and total construction cost.

TABLE 1: Forecasting total cost and project cost level.

\begin{tabular}{lcccccc}
\hline Item & BIM & GIS & OA & PM & Surveillance system & High decoupling \\
\hline BPM & 0.67 & 1.85 & 1.11 & 0.89 & 1.24 & 1.7 \\
BIM & 4 & 1.52 & 1.85 & 2.23 & 3.06 & 3.04 \\
GIS & 5.7 & 4.78 & 3.3 & 3.16 & 5.8 & 3.44 \\
Panoramic & 1.77 & 5.27 & 2.16 & 1.85 & 3.86 & 4.95 \\
Lightweight & 4.89 & 3.65 & 3.44 & 2.48 & 5.82 & 3.1 \\
Integration & 5.76 & 2.23 & 2.45 & 4.99 & & 6.85 \\
\hline
\end{tabular}

TABLE 2: The changing trend of total construction cost under different construction cost levels.

\begin{tabular}{lccccc}
\hline Item & Mult terminal & Surveillance system & High decoupling & Program approval & Quality inspection \\
\hline BPM & 1.82 & 3.56 & 3.47 & 2.2 & 2.26 \\
BIM & 3.44 & 3.79 & 3.97 & 3.69 & 5.34 \\
GIS & 5.2 & 2.48 & 1.36 & 4.99 & 4.68 \\
Panoramic & 4.2 & 3.05 & 3.48 & 6.89 & 2.76 \\
BIMVR & 3.87 & 1.56 & 2.66 & 1.4 & 3.86 \\
Cost & 6.24 & 2.61 & 5.62 & & 3.33 \\
\hline
\end{tabular}

pile of the IoT in the parking lot around the building can be built first, and the electric vehicle can absorb the power through slow charging using IoT.

This is not only favorable to the promotion of electric vehicles but also consistent with the "light storage, direct, and flexible" power distribution transformation of future buildings. It is an important node leading to the cost control path of intelligent building interconnection. This is the development model that organically combines the long-term direction with the short-term tasks. In the design and construction, through the passive technology, the demand of cold, heat, and light provided by the mechanical system is reduced to the minimum, and then, using the optimization techniques of the energy supply system, the energy supply efficiency is improved to the maximum. This should still be the basic requirement for the future development of building and electromechanical systems. Moreover, further development of energy storage and flexible use of energy technology and measures will gradually approach and achieve the future cost control objectives of intelligent building networking.

4.7. Impact of Cost Prediction Function. To further determine the impact of the cost prediction function on the total cost of nonstandard buildings, the relationship between the total cost of the building and the cost grade (0.4BEC 2.0BEC), when $z=1.0$, was analyzed. As shown in Table 3, after introducing the cost prediction function, the total cost under the three schemes is consistent with the regular total cost change trend, and they are both proportional to the cost level. In addition, the total cost indicators of the schemes S0 and S2 overlap, because the value of $K 2$ under the two schemes is similar.

In all of the three schemes, the total cost of each cost grade is lower than the conventional total cost, and the 


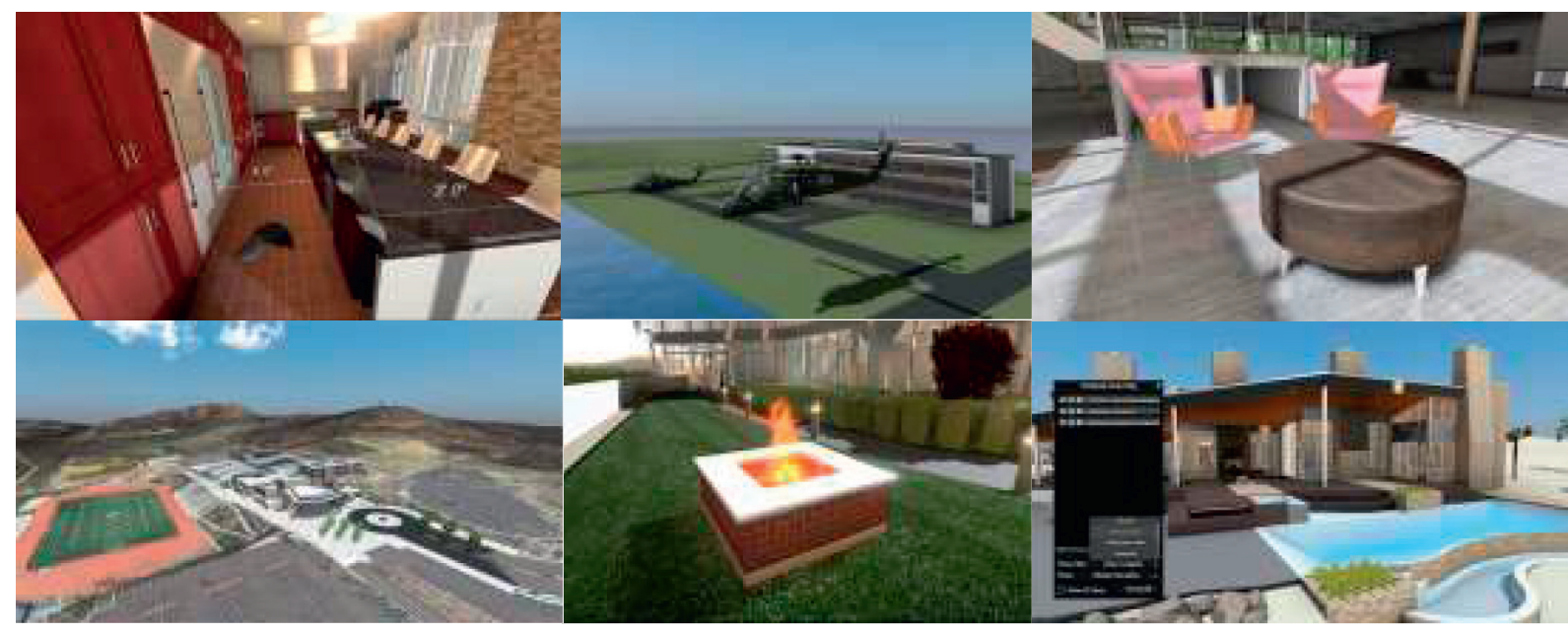

FIgURE 7: BIM visual simulation virtual reality.

TABLe 3: Trend of total cost and conventional total cost.

\begin{tabular}{lccccc}
\hline Item & Program approval & Quality inspection & Construction confession & Engineering inspection & Safety management \\
\hline BIM & 2.99 & 1.65 & 2.88 & 1.04 & 2.75 \\
GIS & 4.07 & 4.88 & 2.61 & 1.31 & 5.39 \\
Panoramic & 2.54 & 3.68 & 6.42 & 4.16 & 4.81 \\
BIMCP & 5.57 & 5.66 & 3.05 & 6.66 & 2.12 \\
Lightweight & 2.01 & 4.59 & 5.05 & \\
\hline
\end{tabular}

ranges of the total cost change rate are $-123.6 \% \sim-21.6 \%$, $-210.3 \% \sim-49.2 \%$, and $-150.2 \% \sim-22.7 \%$, respectively. Likewise, the cost change rate decreases with the increase of the cost level. Therefore, when a certain cost level is exceeded, the cost prediction function loses its effect.

4.8. Refrigeration Cost. The refrigeration cost of intelligent buildings is also an important reference index of cost factors in smart city development. As shown in Figure 8, only when fluorine refrigerant is discharged into the atmosphere of the building, the greenhouse effect can be produced. If the sealing process is improved to achieve no leakage in the process of air conditioning and refrigeration operation, zero emission can be achieved in the buildings. As long as we continue to improve the sealing process, it is possible to eliminate the leakage of nonmobile equipment during operation. For the intelligent building based on IoT, we should develop a new type of fluorine-free air conditioning refrigeration mode to achieve a better refrigeration level.

As shown in Figure 9, the fitting function of the conventional total cost is obtained by curve fitting between the conventional total cost and the engineering cost level. Assuming that the cost prediction function is a quadratic function of one variable related to the project cost level, the unknowns in the cost prediction function are solved according to the three initial conditions given by the scheme maker. The Monte Carlo method was used to simulate different construction cost data to verify the applicability of the cost prediction function. In scheme $S 1$, the minimum total construction cost was expected to occur at 1.0PEB, and the minimum total construction costs of $0.4 \mathrm{BEC} \sim 0.8 \mathrm{BEC}$, 1.0BEC $1.2 \mathrm{BEC}, 1.4 \mathrm{BEC} \sim 1.8 \mathrm{BEC}$, and $2.0 \mathrm{BEC}$ are expected to occur at 1.2PEB, 1.0PEB, 0.8PEB, and 0.6PEB, respectively. Except for the large deviation from the expected value at 2.0BEC, the costs were located near 1.0PEB, and the cost error index of each cost level was less than $7 \%$. Likewise, in scheme S2, the minimum total construction cost was expected to occur at $0.8 \mathrm{PEB}$, and the minimum total construction cost of buildings with cost grades of 0.4BEC 0.6BEC, 0.8BEC 1.2BEC, and 1.4BEC 2.0BEC will occur at 1.0PEB, 0.8PEB, and $0.6 \mathrm{PEB}$, respectively. Except for the construction error index of $0.4 \mathrm{BEC}$, which is $24.04 \%$, the construction cost errors of cost grades were less than $4 \%$. Therefore, it is an effective function for building cost prediction.

\section{Discussion}

The process of urbanization is escorted by the growth of human civilization. The urban management must face several problems such as disorganized urban management, traffic congestion, inadequate environmental control systems, inefficient emergency systems, and unbalanced educational resources. Information systems that control smart cities must have strong computing, sensing, and data application competencies. The advent of intelligent building systems and IoT technology has provided the possibility for the construction of smart cities and associated cost reduction.

Smart city technologies can be employed to solve the problems of urban development and construction. They 


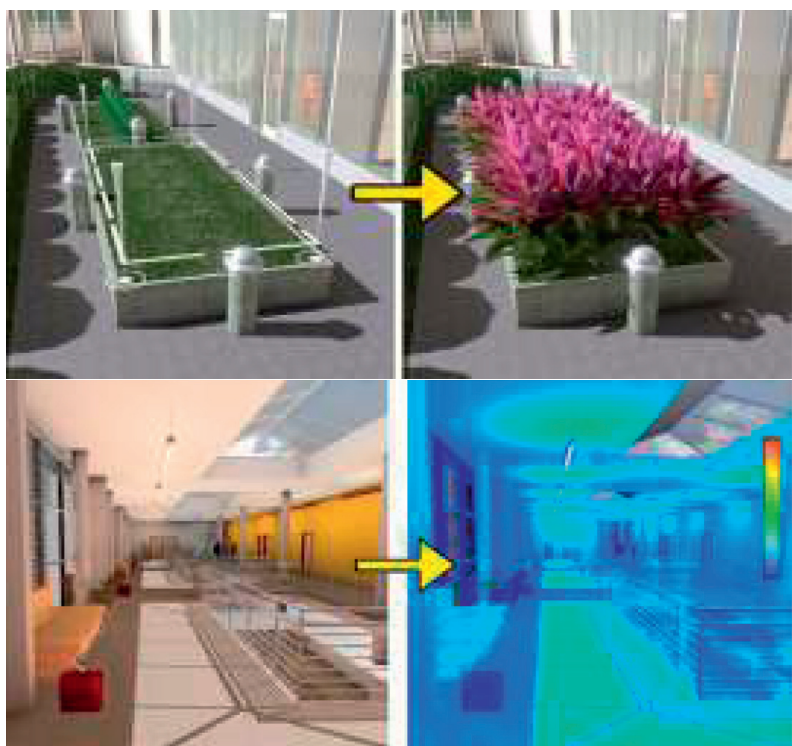

FiguRe 8: Intelligent building refrigeration and dynamic simulation.

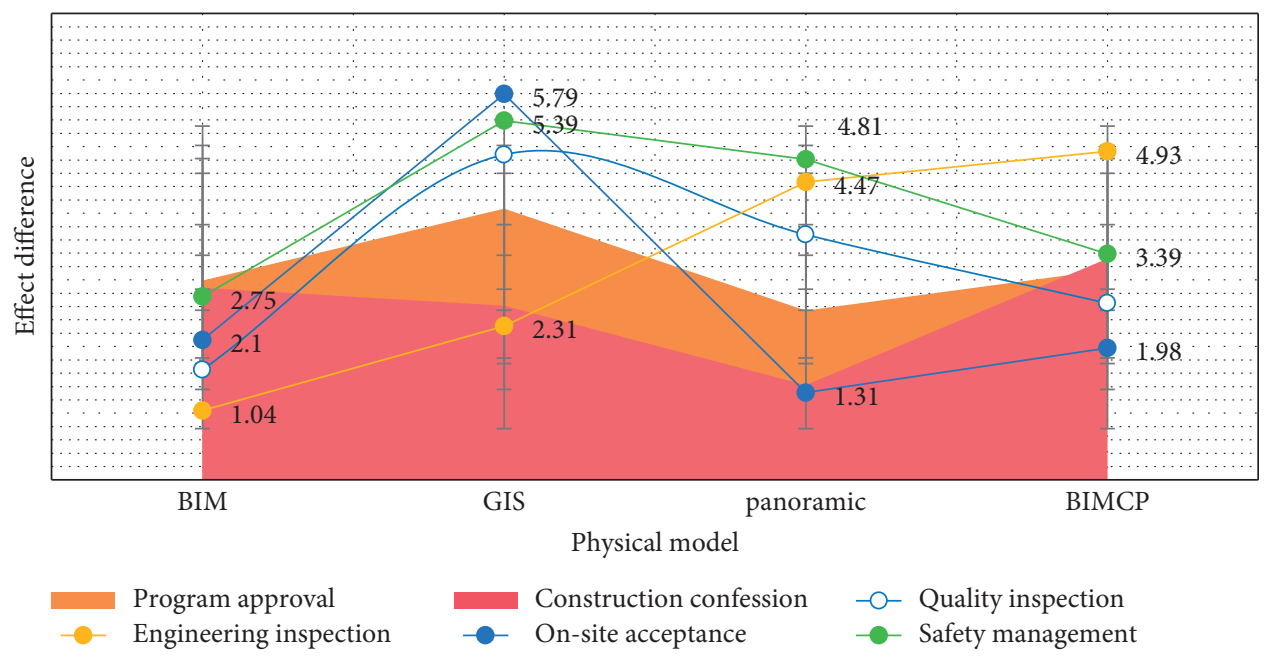

Figure 9: Conventional total cost and project cost level.

have the potential to gather information transparently and systematically, transmit information securely, and process information efficiently and intelligently. They can not only develop urban management, operation efficiency, and level of services but also increase maintainable urban development. In this way, to enable urban expansion, the city can intelligently sense and perform active decision-making, so that the residents can feel the sense of the city provided by intelligence services and IoT applications. Contrary to the concept of fast urbanization and human civilization, big cities all over the world are facing development problems such as pollution, energy shortage, and congestion of traffic.

For building users, the project cost and the initial investment of building are the main factors that restrict the installation of an intelligent building system. Taking a residential building in Nanchang city of China as the research object, this paper developed an algorithm based on the IoT.
We constructed the cost control and cost prediction model of intelligent building. Considering the features and characteristics of the current smart cities' developmental techniques, three engineering cost examples (S0, S1, S2) were constructed. Simulation was carried out for these three examples. When the project cost level was 1.0PEB, the total smart building construction cost under the three schemes was reduced by $50 \%, 100 \%$, and $50 \%$, respectively, compared with the conventional total cost. Likewise, when the cost level was changed from $0.4 \mathrm{BEC}$ to $2.0 \mathrm{BEC}$, the total cost change rate ranges of the three schemes reported were $-124.5 \% \sim-24.8 \%,-250.3 \% \sim-49.8 \%$, and $-182.3 \% \sim-24.8 \%$, respectively This paper reestablishes the cost control and cost prediction model of intelligent building. Experimental results show that the total cost of each cost level of the three schemes is lower than the conventional total cost, and the total cost change rate ranges are $-121.6 \% \sim-27.6 \%$, 
$-210.3 \% \sim-47.2 \%$, and $-150.3 \% \sim-22.3 \%$, respectively. The proposed smart city cost prediction model can reduce project cost, which has great economic significance for the construction of smart cities.

\section{Conclusion}

In this paper, an intelligent cost control method for the construction of smart buildings is proposed. By adding the cost of the IoT systems to the conventional total cost, it can be adjusted to a cost optimization function to meet the needs of building designers. The Monte Carlo method was used to verify the effectiveness of the cost prediction function in the total cost adjustment under different construction costs. Taking a residential building in Nanchang city as an example, three different cost prediction functions (S0, S1, S2) were developed. With the project cost level 1.0PEB, the total construction cost was reduced by $50 \%, 100 \%$, and $50 \%$ for the three schemes, respectively. When the cost level was increased from $0.4 \mathrm{BEC}$ to $2.0 \mathrm{BEC}$, the total cost change rate ranges of the three schemes were $-124.5 \% \sim-24.8 \%$, $-250.3 \% \sim-49.8 \%$, and $-182.3 \% \sim-24.8 \%$, respectively. It is proved that the total construction cost can be adjusted by introducing the cost prediction function, and it is suitable for buildings with a cost level between 0.8BEC and 1.8BEC. In addition, the cost prediction function in scheme $S 1$ can be applied to a wider range of construction cost levels. The proposed model can save time and reduce the project cost for the construction IoT based buildings in smart cities.

\section{Data Availability}

The data used to support the findings of this study are included within the article.

\section{Conflicts of Interest}

The authors declare that they have no conflicts of interest.

\section{References}

[1] T. A. Reddy, "Literature review on the calibration of building energy simulation programs: uses, problems, procedures, uncertainty, and tools," ASHRAE Transactions, vol. 112, no. 1, pp. 226-240, 2006.

[2] X. Gao and P. Pishdad-Bozorgi, "BIM-enabled facilities operation and maintenance: a review," Advanced Engineering Informatics, vol. 39, pp. 227-247, 2019.

[3] H. Zou, Y. Zhou, J. Yang, and C. J. Spanos, "Towards occupant activity driven smart buildings via WiFi-enabled IoT devices and deep learning," Energy and Buildings, vol. 177, pp. 12-22, 2018.

[4] J. Vihola and A. Kurvinen, "Municipal economics of regional development-infill versus greenfield development," Datutop, vol. 34, no. 4, pp. 59-82, 2019.

[5] P. Tuulia, P. Kyösti, and F. Heidi, "Financing major repairs in apartment buildings through infill development: exploring views and benefit requirements of the owner-occupiers," Property Management, vol. 35, no. 5, pp. 508-527, 2017.

[6] H. Ruonavaara, "How divergent housing institutions evolve: a comparison of Swedish tenant co-operatives and finnish shareholders' housing companies," Housing Theory and Society, vol. 22, no. 4, pp. 213-236, 2020.

[7] L. Martti, "Legal challenges in ensuring regular maintenance and repairs of owner-occupied apartment blocks," International Journal of Law in the Built Environment, vol. 2, no. 2, pp. 178-197, 2019.

[8] T. Puustinen and K. Viitanen, "Infill development on collectively owned residential properties: understanding the decision-making process-case studies in Helsinki," Housing, Theory and Society, vol. 32, no. 4, pp. 472-498, 2019.

[9] R. Akbar, "A methodological approach to urban land-use change modeling using infill development pattern-a case study in Tabriz," Ecological Processes, vol. 5, no. 1, pp. 1-5, 2019.

[10] P. Newman and J. Kenworthy, "The transport energy tradeoff: fuel-efficient traffic versus fuel-efficient cities," Transportation Research Part, vol. 22, no. 3, pp. 163-174, 2020.

[11] T. Puustinen, K. Pennanen, H. Falkenbach, and K. Viitanen, "The distribution of perceived advantages and disadvantages of infill development among owners of a commonhold and its' implications," Land Use Policy, vol. 75, no. 4, pp. 303-313, 2018.

[12] G. Stephen and N. Peter, "Understanding infill: towards new policy and practice for urban regeneration in the established suburbs of Australia's cities," Urban Policy and Research, vol. 32, no. 2, pp. 121-143, 2019.

[13] A. L. Hauge, E. Magnus, and K. Denizou, "The meaning of rehabilitation of multi-story housing for the residents," Housing, Theory and Society, vol. 29, no. 4, pp. 358-381, 2019.

[14] J. Jin, J. Gubbi, S. Marusic, and M. Palaniswami, "An information framework for creating a smart city through internet of things," IEEE Internet of Things Journal, vol. 1, no. 2, pp. 112-121, 2014.

[15] C. Sebi, S. Nadel, B. Schlomann, and J. Steinbach, "Policy strategies for achieving large long-term savings from retrofitting existing buildings," Energy Efficiency, vol. 12, no. 1, pp. 89-105, 2019.

[16] V. Benjaoran, "Flowshop scheduling model for bespoke precast concrete production planning," Construction Management and Economics, vol. 23, no. 1, pp. 95-105, 2020.

[17] D. H. Cummings and M. P. J. Egbelu, "Minimizing production flow time in a process and assembly job shop," International Journal of Production Research, vol. 36, no. 8, pp. 2315-2332, 2020.

[18] V. Naranje and R. Swarnalatha, "Design of tracking system for prefabricated building components using RFID technology and CAD model," Procedia Manufacturing, vol. 32, no. 2, pp. 928-935, 2019.

[19] W. Zhang, M. W. Lee, L. Jaillon, and C.-S. Poon, “The hindrance to using prefabrication in Hong Kong's building industry," Journal of Cleaner Production, vol. 204, no. 1178, pp. 70-81, 2018.

[20] R. Bortolini, C. T. Formoso, and D. D. Viana, "Site logistics planning and control for engineer-to-order prefabricated building systems using BIM 4D modeling," Automation in Construction, vol. 98, no. 2, pp. 248-264, 2019.

[21] C. Yuan and L. X. M. Eric, "Unlocking the green opportunity for prefabricated buildings and construction in China," Resources, Conservation and Recycling, vol. 139, no. 4, pp. 259-261, 2018.

[22] S. Schiavoni, F. D'Alessandro, and F. Bianchi, "Insulation materials for the building sector: a review and comparative analysis," Renewable and Sustainable Energy Reviews, vol. 6, no. 8, pp. 988-1011, 2019. 
[23] B. P. Jelle, "Traditional, state-of-the-art and future thermal building insulation materials and solutions-properties, requirements and possibilities," Energy and Buildings, vol. 43, no. 10, pp. 2549-2563, 2019.

[24] X. Q. Yin, H. Q. Li, and H. T. Bo, "Weatherability studies on external insulation thermal system of expanded polystyrene board, polystyrene granule and polyurethane foam," Journal of Wuhan University of Technology-Materials Science Edition, vol. 25, no. 6, pp. 1027-1032, 2019.

[25] J. Lin, H. Xiao, and W. An, "Correlation study between flammability and the width of organic thermal insulation materials for building exterior walls," Energy and Buildings, vol. 82, no. 4, pp. 243-249, 2019.

[26] E. Cuce, P. Cuce, and C. Wood, "Toward aerogel based thermal superinsulation in buildings: a comprehensive review," Renewable and Sustainable Energy Reviews, vol. 34, no. 3, pp. 273-299, 2019.

[27] L. Aditya, T. M. I. Mahlia, B. Rismanchi et al., "A review on insulation materials for energy conservation in buildings," Renewable and Sustainable Energy Reviews, vol. 73, pp. 1352-1365, 2017.

[28] H. Maleki, "Recent advances in aerogels for environmental remediation applications: a review," Chemical Engineering Journal, vol. 300, no. 4, pp. 98-118, 2019.

[29] M. Koebel, A. Rigacci, and P. Achard, "Aerogel-based thermal superinsulation: an overview," Journal of Sol-Gel Science and Technology, vol. 63, no. 3, pp. 315-339, 2019. 